\title{
PRESERVING THE VENETIAN FORTRESS OF BERGAMO: QUICK PHOTOGRAMMETRIC SURVEY FOR CONSERVATION PLANNING
}

\author{
G. Mirabella Roberti ${ }^{1}$, V.M. Nannei ${ }^{2}$, P. Azzola ${ }^{3}$, A. Cardaci $^{4}$
}

Università degli Studi di Bergamo, Italy

1'giulio.mirabella@unibg.it, ${ }^{2}$ virna.nannei@gmail.com, ${ }^{3}$ p.azzola@live.it, ${ }^{4}$ alessio.cardaci@unibg.it

KEY WORDS: Venetian Fortress, Bergamo, UAV photogrammetric survey, 3D modelling, deterioration mapping, scheduled maintenance

\begin{abstract}
:
The historical and cultural relevance of the City Walls built by the 'Serenissima' Republic of Venice in the second half of 16 th century was recognized in 2017 by the insertion of Bergamo, together with other Venetian Fortresses in Italy, Croatia and Montenegro, in the World Heritage List of UNESCO as transnational site. In the framework of the nomination to the WHL, the City Council together with the University of Bergamo started a campaign of studies and surveys aimed to prepare a conservation planning. The goal of this plan is to assure a constant monitoring of this artwork, so that a strict routine of controls, cleaning and small strengthening works would prevent more relevant interventions, which could corrupt the material integrity of the building.
\end{abstract}

This paper delineates the methodological and operational workflow applied to the preparation of the maintenance plan, now in progress, for the Venetian City Walls of Bergamo, where the photogrammetric survey by means of UAV plays an important role. The different working phases, the adopted instrumentation, the difficulties encountered and the choices made are described, and some case studies are also illustrated that represent well the typical problems encountered for the conservation of the Walls.
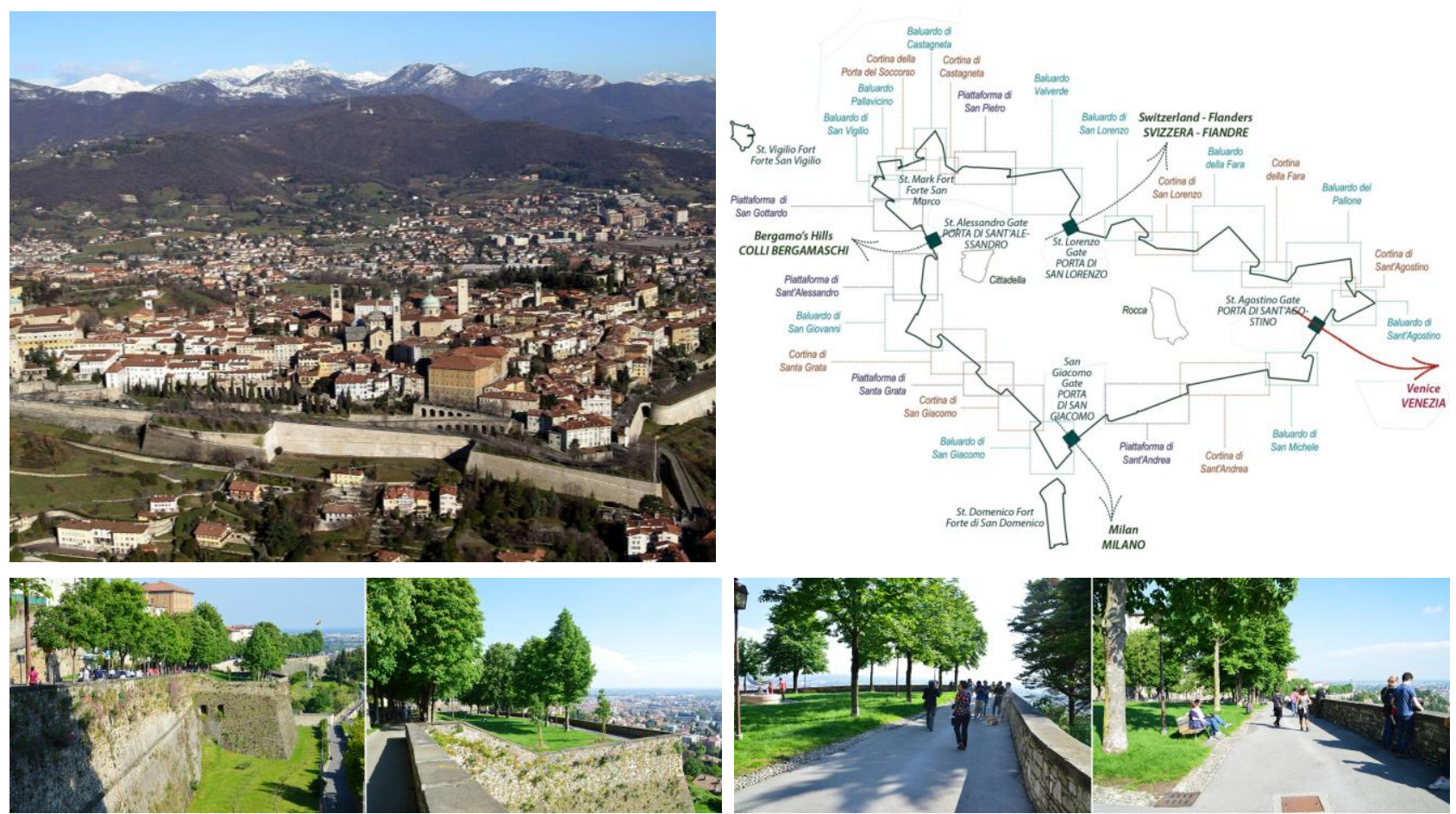

Figure 1. Aerial view form the South of Bergamo city walls and the names of the different portions of the circle.

On the bottom, different sightseens from the promenade (Campus et al. 2017).

\section{INTRODUCTION}

The city walls built by the Serenissima Republic of Venice in the $16^{\text {th }}$ century characterize still today the skyline of the town of Bergamo, defining the relationship between the new city centre designed by architect Piacentini in the $20^{\text {th }}$ century and the ancient core, the so-called Città Alta (High City).
Born with more political than military purposes, the fortress was built as the last western bulwark towards the Milan dukedom in the mainland of Venetian territories, assuming a very important strategic role in the defence of the commercial ways towards North. In fact, the seafaring power of the Republic of Venice was starting its unavoidable decline, due to the loss of the monopoly over pepper and spices trade, challenged by the new sea routes towards the Americas and 
India with the circumnavigation of Africa. This leads to a greater interest for the trading towards Central Europe, conceiving the project for the 'Priula' road, a way that had to connect Bergamo through the Brembana valley to Morbegno in valtellina and to the Grisons canton, allied to the 'Serenissima' and door towards the Central Europe markets, avoiding the passage from the Spanish dominated territories.

Wall construction started in 1561, under the lead of count Sforza Parravicino, and finished only in 1588, encountering huge difficulties from economical and practical point of view. During centuries, the fortress was never attacked, and when at last in Christmas 1796 French troops entered in Bergamo, without one single shooting, the city walls finished definitely their defensive role. Neverless, the civil usage of earthworks and moats by the citizens was already diffused, so that in $19^{\text {th }}$ century, when the Municipality become owner of the top terraces facing south, a boulevard and a public park was created - increasing the height of the wall and adding stone parapets. In this way, the once military spaces were transformed definitely in the citizen's promenade, redefining completely the urban landscape.

The historical and cultural significance of this imposant and well-preserved artwork, all along considered as an essential part of the image of the city, was consecrated in July 2017 by the inclusion in the World Heritage List of UNESCO. The transnational nomination was presented by different fortified cities in Italy, Croatia and Montenegro, comprised in the site 'The Venetian Works of Defence between $16^{\text {th }}$ and $17^{\text {th }}$ centuries: Stato di Terra - Western Stato da Mar'.

In the meantime, the Municipality of Bergamo, in cooperation with the local University and 'Orobicambiente' association, started to set up a maintenance planning for the Walls in order to fight the decay phenomena. The plan forwards a series of actions aimed to "the sustainable maintenance, conceived as a daily care process of the different architectural elements that constitute the 'stone landscape' of Venetian Walls". The conservation works go alongside to a continuous analysis of the state of the sites, which has to be repeated periodically and includes direct 'in situ' inspections and systematic controls, with the cyclic monitoring of the material decay by means of a 3D mapping with aerial photogrammetric survey by drones.

\section{TOWARDS A PLANNED MAINTENACE}

2.1 Maintenance planning: an instrument that put together economic sustainability and protection of historical heritage.

The need of more organic maintenance interventions, or better of a 'planned maintenance', following the definition of $\mathrm{G}$. Urbani (Urbani 2000), is becoming more and more evident and public administration too is feeling that need, opposed to the common practice until now adopted of occasional interventions, following emergency situation or temporary cash availability.

This kind of approach, that encourage executing many minimal and repetitive operations, included preventive interventions and monitoring, on the long term shows undoubtable economic advantages, besides being less invading compared to occasional interventions aimed to restore a supposed initial condition of the architectural heritage. This advantage become particularly relevant for public administrations charged by an enormous amount of heritage (Della Torre, 2010).

So that economic efficiency of planned maintenance becomes the strongest reason for finally adopt the principles that $\mathrm{J}$. Ruskin clearly declared in 'The seven Lamps of Architecture' almost two centuries ago:
"Take proper care of your monuments, and you will not need to restore them [...]. Watch an old building with an anxious care; guard it as best you may, and at any cost, from every influence of dilapidation. Count its stones as you would jewels of a crown; set watches about it as if at the gates of a besieged city [...]; and do this tenderly, and reverently, and continually, and many a generation will still be born and pass away beneath its shadow. Its evil day must come at last; but let it come declaredly and openly, and let no dishonouring and false substitute deprive it of the funeral offices of memory". (Ruskin, 1849: 162-163).

Retracing the steps of the scientific debate on restoration, the constant re-emergence of the instance of conservation is clear, yet only in recent years the problem of maintenance seems to have acquired enough importance to stimulate the development of specific procedures and technical skills.

The Charter of Athens in 1931 already emphasized the need to prefer maintenance works rather than restoration, just as the Instructions for the Restoration of Monuments, issued in Italy by the Ministry of Education in 1938, affirmed the need to prevent, with careful maintenance, any cause of decay of the monuments.

The Charter of Venice, in 1964, reaffirmed the need to adopt maintenance as a practice. A few years later, Giovanni Urbani, follwing the ideas of Cesare Brandi, elaborated the concept of 'planned conservation', based on the systematic control of the environmental conditions in which the cultural asset is placed, in order to slow down the decay phenomena, and on well-timed maintenance works.

The goal of planned conservation is therefore to contain emergencies through prevention. This type of approach finally debuted with the "Pilot Plan for the Conservation of Cultural Heritage in Umbria" (Urbani, 1976) and was subsequently developed in the project of the Istituto Centrale del Restauro of the Risk Map of Cultural Heritage (Grano, 2010).

In 2000, the Charter of Krakow once again reaffirmed the concepts already expressed by the previous position papers; in the same period the Italian legislation, for the first time, recognized the concept of maintenance applied to cultural heritage, and the issue of the proper definition of this term aroused. The impact of maintenance works is often underestimated: thought as a harmless small restoration, it is often not limited to preventive actions, but includes in practice interventions that damage the material authenticity of the building, beyond repair. The lack of a clear and unequivocal definition of maintenance can determine a serious risk for the architectural heritage: the unbridgeable gap between contemporary and traditional construction techniques makes impossible the continuous maintenance that was usual in the past (Talamo, 2010).

This risk is aggravated by the fact that Italian law gives different meanings to the term 'maintenance' for new or historic buildings. For this reason, the expressions coined by Urbani and proposed again by Della Torre, 'planned conservation' or 'conservation plan' are preferable for cultural heritage instead of the 'maintenance plan' used by the legislation. An interesting analysis of the issues in defining the term 'maintenance' in the Italian law is proposed in the second volume of the text "Procedures and methods of building maintenance" (Talamo, 2010).

I The maintenance plan was introduced in Italy by Law no. 109/1994, which requires the obligation to include the maintenance plan in the executive project for public works. The D.P.R. 544/99 establishes the articulation of the plan in three documents, the "Maintenance manual", a data collection tool for the elaboration of the maintenance program, the "Maintenance 
program", which defines the modalities and timing of the periodic checks on the state of the building, and the "User manual", which contains the recommendations for a correct use of the property.

The maintenance plan defined in these regulations is a tool aimed at new buildings, structured according to performance logic not applicable to historic buildings. In fact, it is not possible to apply the concept of the existence cycle to the historical building and the idea of restoring presumed initial performance levels is in direct contrast with the instances of preservation of the authenticity of the artefacts. The need to implement prevention strategies for historic buildings decay is introduced by the D.P.R. n. 554/1999.

The law was the basis for the drafting of the Guidelines of the Lombardy Region for the Maintenance Plan (Della Torre, 2003). These are recommendations, without binding value, for the drafting of an organic and detailed preventive conservation plan.

The obligation to prepare the maintenance plan in public works concerning cultural heritage, as part of the definitive and executive project, was sanctioned by the The Decree No 207/2010 of the President of the Republic.

The definition of the term "maintenance" for historical buildings was introduced by the Legislative Decree No. 42/2004, "Code of cultural heritage and landscape", as the set of activities and interventions aimed at controlling the state of the cultural heritage and maintaining the integrity, functional efficiency and identity of the asset and its elements. The Decree No 207/2010 of the President of the Republic specifies that maintenance, for works concerning cultural heritage, consists of a series of periodically repeatable and specialized technical procedures, aimed at maintaining the historical-artistic characteristics, the authenticity of the materials and the functionality of the building (Talamo, 2010).

Despite these definitions highlight the issue of conservation of the materials, and not just the formal aspects of historical building, the Legislative Decree No. 222/2016, updating of the Consolidated Law on Building, as well as not dealing with the peculiarities of maintenance for the historical buildings, defines the restoration and conservative restoration as works that, respecting the typological and formal elements of the building, can renew its elements and eliminate the elements which are regarded as extraneous. Therefore, the idea of restoration conceived by the legislator, not only allows the "elimination of superfluous", but also the possibility of replacing the original materials of the buildings.

\subsection{The planned maintenance of the Venetian walls of Bergamo: the challenge of an urban site}

The environmental context highly influence the conservation state of artworks, particularly for masonry walls, allowing the growth of volunteer vegetation on the masonry face and at the feet of the walls. The roots may damage the masonry face, penetrating in the chinks and causing their enlargement until the stones of the face are detached and expelled. In addition, the trees grown on the border of the glacis in the private estates weaken the top of the walls until the rounded stones that belong to the cordon fall down.

From one side, the volunteer vegetation removal appears as a recurrant problem, wich can be weel planned and taken under control with a convenient rate, on the other the accurate repair of the disconnections and voids caused by the trees request quick interventions, to be eexecuted with the requested attention to the historical matter but also with the due efficiency.

In the past, the periodic action of removing the vegetation has mainly concerned the most 'visible' parts of the perimeter of the walls that are those facing the lower city on the southern front. On the contrary, some less accessible parts, especially in the part that constituted the so-called 'Fort of San Marco' towards the hill of San Vigilio, suffer from long periods of neglect in which the vegetation has grown undisturbed, causing considerable damage to the wall and at the top portion of the wall itself.

Paradoxically, the Municipal Administration has made itself available to take over the maintenance of the entire perimeter, but not to take over the ownweship of the statal property, thus avoiding the obligation of maintenance, as civil and criminal liability for possible damage to persons or things due to the absence of preventive conservation actions. In the case of walls of Bergamo, the definition of the competences connected to the complex regime of ownership of the artifacts is one of the principal problems to solve. The original military function in fact left the legal ownership of the walls to the state property of the successive governments (Cisalpine Republic, Kingdom of Lombardy-Veneto, Kingdom of Italy, Italian Republic) themselves. To be precise, this property only concerns the stone masonry structures of the actual walls, while the sides on the top of the bulwarks and curtains were already alienated in the first half of the nineteenth century, as well as the underlying lands comprising the moats, and other parts of the complex defensive system, soon absorbed by crops and private gardens. A part of the stands, which became municipal property in 1825 at the behest of that time (...), was used between 1829 and 1841 for the creation of a panoramic urban promenade and the avenue of the walls, between Porta S. Giacomo and Porta S. Alessandro, concluded with the arrangement of the square of Colle Aperto. Even the four main urban gates became municipal property, while other spaces considered less significant were purchased by private individuals. As already mentioned, the walls and the underground spaces (such as the gunboats and the access tunnels) remained state-owned, with an effect above all of 'passive protection', linked to the lack of interest in a direct income from the buildings or land, but with very little resources invested for the maintenance of such an extensive artifact.

On the one hand, the obligation to provide for the preservation of a bound monumental asset falls on the property (art. 30 of the Cultural Heritage and Landscape Italian Code), in the case of the State property these obligations are in fact little pressing. This is why the Municipality of Bergamo has been forced induced to take care of maintenance, also due to the strong pressure from the citizenry that has always felt the Walls as a collective heritage. This was possible activating specific conventions with the State Property and the private subjects involved, as well as with associations of citizens who voluntarily lend their work for routine maintenance work.

On 20/03/2015, an agreement was signed by the State Property Office (the largest owner of the Venetian Walls) and the Orobicambiente Onlus association for the periodic execution of works to remove weeds. This among conferred title to the Municipality to participate in tenders for the maintenance and enhancement of the monumental asset, such as the one announced by the Cariplo Foundation 'Good practice of heritage conservation' in the 2015 Art and Culture group, which provided a loan of about $€ 300,000$ for the realization of a project comprising both urgent maintenance operations and the preparation of a periodic inspection and maintenance program to be repeated over time. 

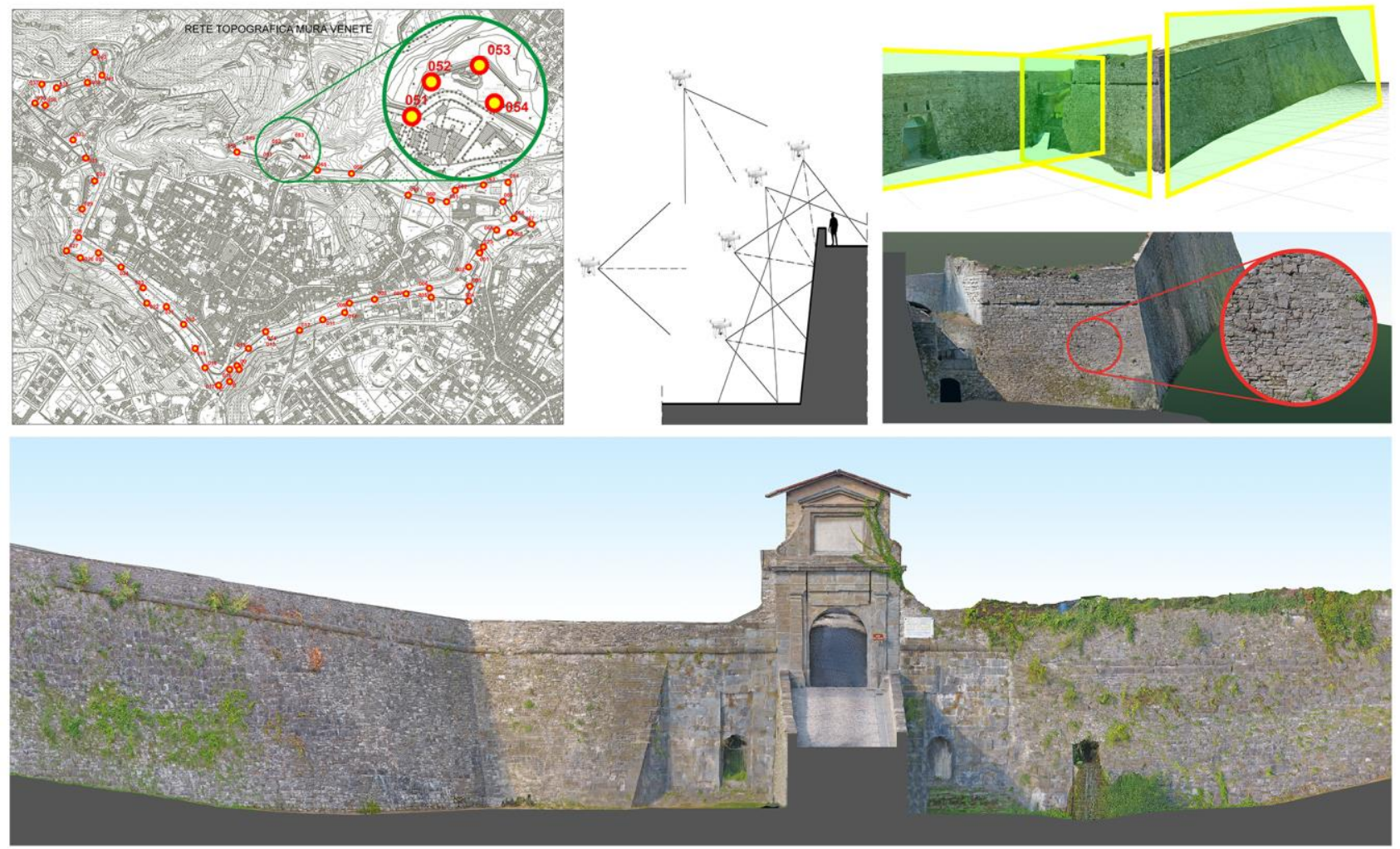

Figure 2. The phases of the photogrammetric acquisition and creation of the point cloud model: definition of the reference point network, UAV flight project and creation of the 3D model. On the bottom, ortographic projection of the walls near St. Lorenzo Gate.

\section{WORKING TOOLS}

\subsection{Integrated survey}

The coordination of the operations, which ranges from the maintenance of the parapets along the pedestrian paths (mainly those adjacent to the Viale delle Mura) and the replacement of the deteriorated stone covers, to the removal of the infesting vegetation, underlined the need for a more flexible and detailed operational tool. It must be able to keep the current situation under control, reporting the state of affairs before and after the interventions carried out, to identify in a timely manner any repairs needed to avoid further damage and the operating procedures to be followed each time. The operational tool must have the usage flexibility of a geographic-territorial database $(G I S)$ with the detailed accuracy of a geometric-material survey. At at the same time it must allow a sufficiently expeditious realization in order to be repeated over time, thus acquiring a diachronic dimension.

For these reasons, the choice has been primarily on an aerial photogrammetric survey using 'drones', or more precisely Unmanned Aerial Vehicle (UAV). Trough the use of increasingly advanced software they allow the acquisition of three-dimensional texturized models. That is the projection onto the obtained surfaces of the acquired photographic images, increasing the informations and the representativeness of the model.

The combination of the geometric precision achievable with direct and possibly geo-referenced surveys, with the speed of execution and the richness of detail obtainable with photography is an objective that can be pursued with the currently available tools. Moreover, they are also constantly evolving: for example, the creation of a topographic support detailed analysis, for particular degradation conditions or any existing failures.

The realization of the models took place sector by sector using the 3DFLOW Zephyr Aerial@ software. It allowed realizing the three-dimensional model with texture of the surface of the walls, through a workflow started by the original images.

The overall three-dimensional model is the result of the combination of single stretches of minor extension. This has proved to be necessary by evaluating the times and hardware resources that are required in the processing phase. In this way, each individual part was computationally manageable, although in order to obtain the defined level of detail it was necessary to carry out a considerable amount of processing. The individual sections have a straight length generally of less than $250 \mathrm{~m}$ and they are defined by the presence of at least five topographic vertices with known spatial coordinates arranged within each of them. This characteristic provides an adequate redundancy useful for the correct spatial positioning of the model.

The EXIF data of the images are the starting point for a preliminary orientation of the chambers (structure from motion) which is based on the automatic recognition of significant features present in each image, thus obtaining a 'sparse point cloud'. Despite the choice of settings that promote quality and precision at the expense of processing time, the average error that characterizes the control points of the model in this phase reaches a few tens of centimeters.

However, this procedure was useful in the next phase: in fact, the definition of a sparse point cloud speeded up the manual identification of the targets in different single images. After assigning the spatial coordinates of the topographic vertices, the model was aligned with the $3 \mathrm{D}$ constraints identifying the reliable points, free from accidental errors. The procedure produces a new scattered point cloud characterized by much more contained errors, in the order of a few millimeters. Typically, the procedure continues with the elaboration and 
manual refinement of the 'dense point cloud', with the creation of the triangular mesh surfaces (mesh) and with the projection onto the surfaces of the most effective frames to reconstruct the image of the detected object (textured mesh). Finally, textured meshes were exported by an exchange format to be imported into the overall model of the entire walls circuit.

From the models related to the single parts it was also possible to extract orthographic projections on vertical planes, parallel to the prevailing planimetric trend of the stretch of walls, in the predetermined scale.

The 'orthophotos' produced in this way, together with perspective representations of the realized model, will be made available to the Technical Office of the Municipality of Bergamo. They will be a basis for mapping the state of conservation of the circle of the 'Venetian Walls', accompanied by a cataloging of the degradation cases encountered and the case history of the planned maintenance interventions.

\subsection{Structure of the maintenance plan}

The Maintenance Plan, according to the art. 40 of the D.P.R. $544 / 99$ and subsequent updates, is the supplementary document to the executive project, which envisages, plans and programs the maintenance activities of the intervention in order to maintain its functionality, quality characteristics, functional efficiency and economic value over time. In the case of cultural heritage, Conservation Plan is the appropriate expression to use. It must preserve the values of authenticity, identity and material permanence (Cecchi and Gasparoli, 2011).

The preparation of the Venetian walls of Bergamo conservation plan, currently still in progress, is based on the indications contained in the guidelines for the architectural heritage maintenance plan promoted by the Lombardy region (Della Torre, 2003). It also consider the case studies proposed by Cecchi and Gasparoli for the development of plans and maintenance programs of architectures of archaeological interest (Cecchi and Gasparoli, 2010 and Cecchi and Gasparoli, 2011). It is structured, as we have seen, in three different documents: the Technical manual, the Conservation program and the User manual, supported by an information system for recording and managing incoming and outgoing data that must allow an easy updating of the Conservation plan. The Technical manual is a document that contains all necessary information for the correct maintenance of the asset. It is divided into tabs and must contain the unique cataloging of all the elements of the product, accompanied by descriptions and graphic representations, a characterization of the expected anomalies and maintenance procedures that can be performed by users or specialized personnel.

In the case of the walls of Bergamo, a first indexing of the buildings was carried out according to the traditional subdivision adopted also during the previous surveys (CGB, 1980), in doors, viaducts, bulwarks, platforms and curtains. The document reports the location, the description, some historical data and the list of recent interventions have been reported for each building, in addition to the identification of the individual components. The guidelines provide for the identification of the technological elements according to UNI 8290-1:1981, but the peculiarity of the building required an adaptation of the adopted terminology. For example, using the item Roof fall protection system in door equipement. A subsequent integration will be carried out over time for each element, with the description of the specific materials, the construction techniques, the previous treatments and the state of preservation. The analisys of these components in the first phase was made at the building scale because of the extension of the wall circuit.
The documentation must match with the survey of the state of art, starting from the geometric survey that constitutes the basis for qualitative studies (Della Torre, 2003).

In the case of the walls, the use of aerial photogrammetry has allowed a 1: 200 scale survey, which must be integrated over time until reaching the 1:50 scale. It is necessary for recording the results of the checks carried out at sight and at computation of the interventions envisaged following these checks and any diagnostic investigations.

In general, the conservation interventions require a punctual differentiation for the single parts of the building, but some considerations can be made about an extended artifact like a wall circuit, which, at the same time, presents a certain degree of homogeneity among its elements. Through the visual inspections, the prevalence of some alteration and degradation phenomena that occur along the entire perimeter was observed. Considering the difficulty of producing analytical mappings of the phenomena found for all the elements, it was decided to proceed with case studies, on which intervention guidelines can be prepared.

Specifically, the most significant alteration phenomena identified and collected in special indexing are linked to the widespread presence of vegetation, which in the worst cases has caused the masonry to fail, in addition to the perishability of the materials constituting the walls and the covers of the parapets.

Regarding the parapets, the section of the S. Grata screen was examined. It was the subject of one of the interventions financed by the Cariplo tender. The part, surveyed by photogrammetry from the ground, has been the object of mapping and filing of the degradations and of the interventions concerning the punctual replacement of sandstone covers, the restyling of mortar joints and the punctual integration of the lost stone elements. The issue of parapets maintenance is a crucial node for the local administration as it effects the safety of users, but also determines the problem of the proliferation of weeds on the underlying masonry. The lack of regulation of rainwater drainage, in fact, determines a proliferation of vegetation at the interface between the parapet and the walls. The solution proposed was to seal the foot of the parapet using a layer of mortar that leads the water to drain in the opposite direction to that of the walls. This solution will be applied over time to all the parapets.

The second case study concerned the cleaning operations, the grouting of the mortar joints and the integration of the portions of masonry removed by effect of the infesting vegetation along the Porta San Giacomo viaduct. The recording of the state of affairs and the indication of the interventions, in this case, was carried out using orthophotos taken from the model built with drones. However, in the future it will be necessary, through the repetition of the flights and the possible integration with photogrammetry from the ground and laser scanner, proceed to a graphic restitution at more detailed scale than has been possible in this first phase of intervention.

A last important case study will be the bulwark of Valverde, where the lack of vegetation control has determined the worst damages to the masonry. For this section, the model will be integrated with ground-based, photogrammetric and laser surveys, in order to achieve a scale of detail that allows considerations to be made regarding the deformations present, as well as the timely recording of the results of visual observations and the computation of necessary interventions.

The drawing up of the Conservation program consists in the chronological planning of the inspection and maintenance activities foreseen in the technical manual and focuses on the annual visual inspections of each building of the walls and on the annual cleaning of the vegetation performed by the volunteers. 
The target of the User manual is to involve people in the care of the assets and, in the case of walls, this plan in particular collects the suggestions addressed to the owners of the land at the bottom and at the top of the walls for the control of vegetation

growth.

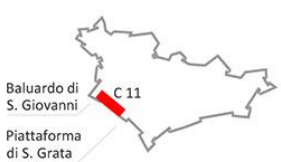

KEYPLAN

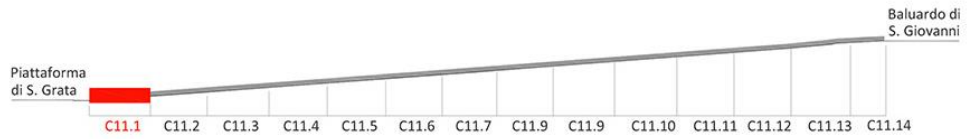

KEYSECTION

PROSPETTO 1.1

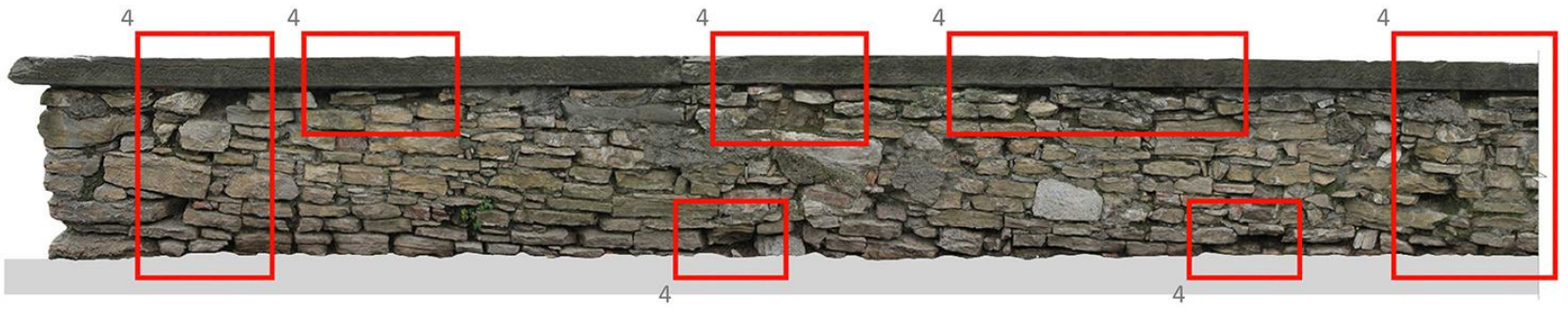

PROSPETTO 1.2

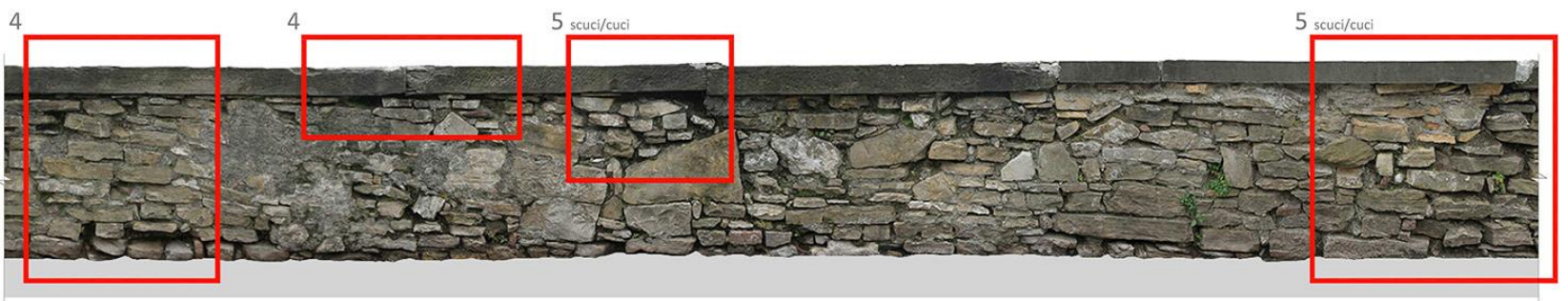

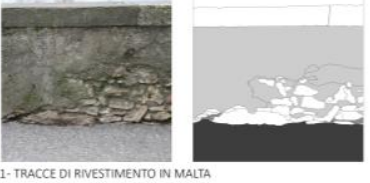
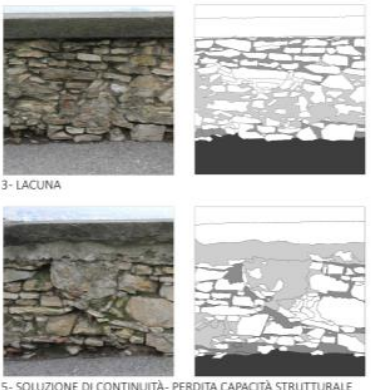
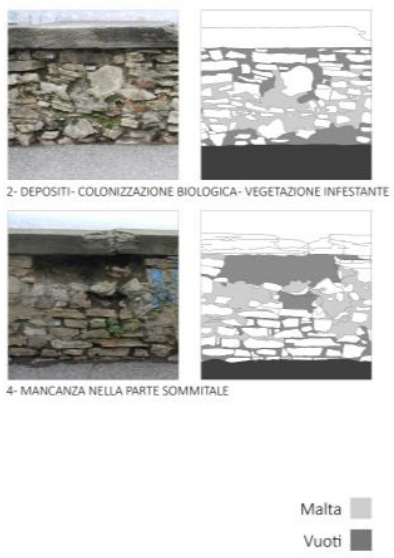

Piano di calpestio
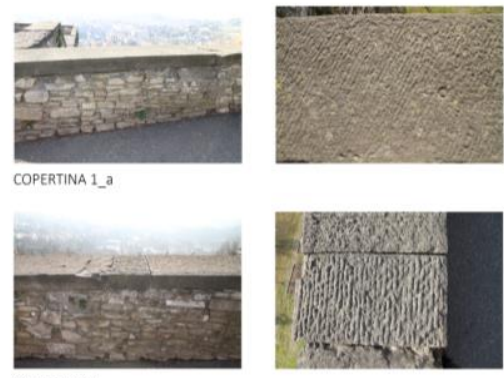

COPERTINA 3
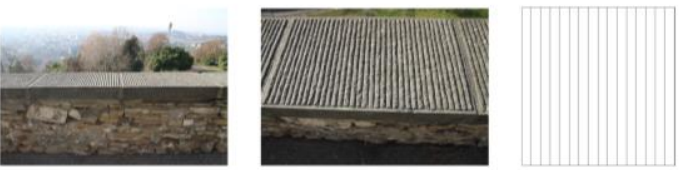

Figure 3. Detail of the parapet along the 'Cortina di Santa Grata' with front and top deterioration mapping (Campus et al. 2017).

\subsection{Future developments}

The Conservation plan is a tool that must be updated over time. For this reason, it needs an effective data collection structure, capable of systematizing informations of metric and qualitative nature. In this sense, the three-dimensional model offers the best opportunities if it will be the basis for the construction of a BIM model.

To achieve this result, a refinement of the geometric data collected so far will have to be carried out in the coming years, together with the gradual completion of the mapping of the constituent materials and the alteration phenomena of each element of the walls.

\section{CONCLUSIONS}

The work carried out has made it possible to offer to the Public Administration an important resource in terms of knowledge of a very extensive and much loved, but little-known artifact. The support of the University to the work of the volunteers ensured 
an adequate scientific rigor to the procedure followed, while substantially containing the costs of the operation.

The repetition of the photogrammetric survey at fixed intervals, to be possibly expected in the maintenance program, can allow a comparison over time of the evolution of the degradations. For example, the analysis of the infesting vegetation speed of regrowth will be possible to establish a ranking of intervention priorities. All this however, it requires to automate and simplify the processing procedures of the acquired images, which remain very laborious and still require very long calculation times. It will also be possible to integrate the geometric model with punctual information of other nature, such as any repairs carried out, the identification of past interventions and their chronology, the quality of the materials used and their possible origin. In this way, it will be possible also integrate, where it is necessary, the level of detail of the model with more accurate tools, such as close-ups from the ground or laser-scanning surveys.

\section{ACKNOWLEDGEMENTS}

The authors would like to acknowledge Comune di Bergamo e Orobicambiente Onlus for giving the photograms aquired by drone, arch. Campus and arch. Castelli for the contribution in the analysis of masonry faces and stone covering decay. The financial contribution of 'Fondazione Cariplo', who allowed the development of this project, is gratefully acknowledged.

\section{REFERENCES}

[AAT] Azienda Autonoma di Turismo, 1977. Le mura di Bergamo. Bergamo: AAT.

[ASLAB] Ateneo di Scienze, Lettere ed Arti di Bergamo, 1990. "1588-1988. Le mura di Bergamo", Atti dell'Ateneo di Scienze, Lettere ed Arti di Bergamo 49. Bergamo: Edizioni dell'Ateneo.

Barazzetti, L., Brumana, R., Oreni, D., Previtali, M., and Roncoroni, F., 2014. "True-orthophoto generation from UAV images: Implementation of a combined photogrammetric and computer vision approach", ISPRS Ann. Photogramm. Remote Sens. Spatial Inf. Sci., II-5, 57-63.

[CGB] Collegio dei Geometri di Bergamo (ed.), 1980. Rilievi e disegni delle mura venete. Bergamo: Tipografia Bergamasca.

Della Torre, S. (ed.), 2003. La conservazione programmata del patrimonio storico architettonico. Linee guida per il piano di manutenzione e il consuntivo, Milano: Edizioni Angelo Guerini e Associati.

Della Torre, S., 2010. "Conservazione programmata: i risvolti economici di un cambio di paradigma”. Il capitale culturale 1 , 47-55.

https://doi.org/10.13138/2039-2362/30

Federman, A., Santana Quintero, M., Kretz, S., Gregg, J., Lengies, M., Ouimet, C. and Lalibert, J., 2017. "UAV photogrammetric workflows: a best practice guideline", Int. Arch. Photogramm. Remote Sens. Spatial Inf. Sci., XLII-2/W5, 237-244.

Campus G., Castelli I. F., Nannei V. M., Mirabella Roberti, G., 2017. Attraverso il parapetto: le Mura Venete di Bergamo da architettura militare a spazio urbano condiviso, in D.R. Fiorino (a cura di), Military Landscapes. A future for military heritage.
Atti del convegno, La Maddalena (SS) 21-24 giugno 2017. Milano: ed. Skirà.

Cecchi, R. and Gasparoli, P., 2010. Prevenzione e manutenzione per $i$ beni culturali edificati: procedimenti scientifici per lo sviluppo delle attitività ispettive. Il caso studio delle aree archeologiche di Roma e Ostia Antica. Firenze: Alinea Editrice.

Cecchi, R. and Gasparoli, P., 2011. La manutenzione programmata dei beni culturali edificati: procedimenti scientifici per lo sviluppo dei Piani e dei Programmi di Manutenzione. Casi studio su architetture di interesse archeologico a Roma e Pompei. Firenze: Alinea Editrice.

Grano, M.C., 2010. "Il tempietto di San Gerardo a Potenza. Quaderno di conservazione programmata, ricerca storica, analisi minero-petrografiche e proposta di una metodologia conservative". Quaderni della Regione Basilicata. Potenza: Consiglio Regionale della Basilicata.

Quatremère de Quincy, A.C., 1832. Dictionnaire historique d'architecture comprenant dans son plan le notions historiques, descriptives, archaologiques, biographiques, théoriques, didactiques et pratiques de cet art. Paris: Librairie d'Adrien Le Clère et Cie.

Ruskin, J., 1849. The Seven Lamp of Architecture, New York: John Wiley.

Talamo, C., 2010. Procedimenti e metodi della manutenzione edilizia. Il piano di manutenzione: Ambiti di applicazione, strategie e procedure. Molinari C. (ed.), 2. Napoli: Sistemi Editoriali - Gruppo Editoriale Esselibri Simone.

Urbani, G., 2000. Intorno al restauro. Milano: Sikra. 